\title{
ARTICLE
}

\section{Facile scission of isonitrile carbon-nitrogen triple bond using a diborane(4) reagent}

Hiroki Asakawa', Ka-Ho Lee ${ }^{2}$, Zhenyang $\operatorname{Lin}^{2} \&$ Makoto Yamashita ${ }^{1}$

Transition metal reagents and catalysts are generally effective to cleave all three bonds (one $\sigma$ and two $\pi$ ) in a triple bond despite its high bonding energy. Recently, chemistry of single-bond cleavage by using main-group element compounds is rapidly being developed in the absence of transition metals. However, the cleavage of a triple bond using non-transition-metal compounds is less explored. Here we report that an unsymmetrical diborane(4) compound could react with carbon monoxide and tert-butyl isonitrile at room temperature. In the latter case, the carbon-nitrogen triple bond was completely cleaved in the absence of transition metal as confirmed by $\mathrm{X}$-ray crystallographic analysis, ${ }^{13} \mathrm{C} N \mathrm{NM}$ spectroscopy with ${ }^{13} \mathrm{C}$ labelling and DFT calculations. The DFT calculations also revealed the detailed reaction mechanism and indicated that the key for the carbon-nitrogen triple-bond cleavage could be attributed to the presence of nucleophilic nitrogen atom in one of the intermediates.

\footnotetext{
${ }^{1}$ Department of Applied Chemistry, Faculty of Science and Engineering, Chuo University, 1-13-27 Kasuga, Bunkyo-ku 112-8551, Japan. ${ }^{2}$ Department of Chemistry, The Hong Kong University of Science and Technology, Clear Water Bay, Kowloon, Hong Kong. Correspondence and requests for materials should be addressed to M.Y. (email: makoto@oec.chem.chuo-u.ac.jp) or to Z.L. (email:chzlin@ust.hk).
} 
A triple bond having three shared electron pairs between two atoms is known as one of the strongest chemical bonds. In spite of the large bonding energy, complete cleavage of the three (one $\sigma$ and two $\pi$ ) bonds in a $\mathrm{C} \equiv \mathrm{C}$ triple bond of an alkyne molecule or in a $\mathrm{C} \equiv \mathrm{N}$ triple bond of a nitrile molecule under oxidative or acidic condition is common in general organic chemistry. In addition to the well-established chemistry of alkyne metathesis ${ }^{1}$, some stoichiometric ${ }^{2-4}$ and catalytic $^{5-11}$ reactions for complete cleavage of a $\mathrm{C} \equiv \mathrm{C}$ triple bond are also known with transition metal (TM) reagents and catalysts. However, only two examples about the cleavage of a $\mathrm{C} \equiv \mathrm{C}$ triple bond without TMs have been reported using tandem- and multistep reactions under harsh condition ${ }^{12,13}$. Moreover, cleavage of the $\mathrm{C} \equiv \mathrm{O}$ triple bond in carbon monoxide $(\mathrm{CO})$ is widely known as the Fischer-Tropsch process in the presence of a TM catalyst $^{14}$. Recent development of TM catalysts enabled us to cleave the $\mathrm{N} \equiv \mathrm{N}$ triple bond in dinitrogen for the formation of ammonia $^{15-17}$. Several catalytic ${ }^{18}$ and stoichiometric ${ }^{19,20}$ cleavage reactions of a $\mathrm{C} \equiv \mathrm{N}$ triple bond were also reported with use of TM catalyst and reagent ${ }^{21-23}$. Although some p-block element compounds could also react with CO ${ }^{24-38}$ or isonitriles ${ }^{28,39,40}$, the strongest $\sigma$-bond among the three bonds in a triple bond remained intact in all cases.

On the other hand, chemistry containing Lewis-base adduct of $s p^{2}-s p^{3}$ diborane(4) compounds has been quickly developed recently. After the isolation of the first example of base adduct of bis(catecholato)diborane $(4)^{41-45}$, a series of the $s p^{2}-s p^{3}$ diborane(4) compounds were applied as a boron source for copper-catalysed $\beta$-borylation of $\alpha, \beta$-unsaturated carbonyl compounds in the absence of additional base $\mathrm{b}^{46-48}$, as a hydrogen donor for radical reduction ${ }^{49}$ and as reactive compounds to undergo rearrangement reactions ${ }^{50-53}$. Some Lewis-base-catalysed $\beta$-borylation reactions of $\alpha, \beta$-unsaturated carbonyl compounds were also considered to involve such $s p^{2}-s p^{3}$ diborane(4) intermediates ${ }^{54-61}$. Herein, we report a complete cleavage reaction of $\mathrm{C} \equiv \mathrm{N}$ triple bond in isonitrile by using unsymmetrical diborane(4) compound, involving $s p^{2}-s p^{3}$ diborane(4) intermediates supported by density functional theory (DFT) calculations.

\section{Results}

Synthesis and reactivity of diborane(4) with $\mathrm{CO}$ and ${ }^{t} \mathrm{BuNC}$. Synthesis of the unsymmetrical diborane(4) 2, its reactions and characterization of the resulting products are summarized in Fig. 1 (see also, Supplementary Figs 1-15, Supplementary Tables 1 and 2, and Supplementary Methods). Reaction of 1 with mesitylmagnesium bromide gave 2 in $49 \%$ yield. The ${ }^{1} \mathrm{H}$ NMR spectrum of 2 showed $C_{2 v}$ symmetrical pattern of signals. Two broad ${ }^{11} \mathrm{~B}$ NMR signals were observed at $\delta_{\mathrm{B}} 34$ and 89 p.p.m., indicating the selective conversion of one (pinacolato)boryl group to a dimesitylboryl group. Broadening of a ${ }^{13} \mathrm{C}$ NMR signal at $\delta_{\mathrm{C}} 144.2$ p.p.m. also confirmed the connection between the mesityl groups and a quadrupolar boron nucleus. $\mathrm{X}$-ray crystallographic analysis of 2 revealed twisted orientation described by the dihedral angle of $\mathrm{O} 1-\mathrm{B} 1-\mathrm{B} 2-\mathrm{C} 16$ in contrast to the case of 1 (Supplementary Fig. 16) ${ }^{62}$. DFT calculation showed that the vacant $p$-orbital of the boron atom in the Bpin moiety slightly contribute to the LUMO of 2 (Supplementary Figs 17-18), which mainly consisted of the vacant p-orbital of the boron atom in the $\mathrm{BMes}_{2}$ moiety, in spite of the twisted structure.

The unsymmetrical diborane(4) 2 reacted with $\mathrm{CO}$ or ${ }^{t} \mathrm{BuNC}$ to give a variety of products (Fig. 1). A benzene solution of 2 was exposed to $\mathrm{CO}$ at room temperature for $30 \mathrm{~min}$ to give pale yellow solids of 3 in $20 \%$ isolated yield. X-ray crystallography for 3 showed incorporation of two CO molecules (it should be noted the complete assignment of atomic order in 3, 5 and $\mathbf{6}$ would be difficult due to small difference in electron density of the second period elements; see below and Fig. 2). The O3-C7 [1.406(3) $\AA$, C7-B2 [1.459(4) $\AA]$ and B2-C8 [1.492(4) $\AA]$ bonds are shorter than the conventional single bonds, and C8-O4 [1.144(3) $\AA]$ is slightly longer than the $\mathrm{C} \equiv \mathrm{O}$ bond of free $\mathrm{CO}$ molecule $(1.1283 \AA)^{63}$. These data proposed resonance structures of 3 and 3' with a characteristic conjugated O-C-B-C-O linkage giving a pale yellow colour (Supplementary Fig. 19 for ultraviolet-visible spectrum and Supplementary Tables 3 and 4 for time-dependent DFT calculation). Thus, compound 3 could be described as CO-coordinated alkoxyboraalkene. Reaction of $\mathbf{2}$ with one equivalent of ${ }^{t} \mathrm{BuNC}$ gave a colourless cyclized product 4 in $50 \%$ yield through scission of the isonitrile $\mathrm{C} \equiv \mathrm{N}$ triple bond and of a $\mathrm{C}\left(\mathrm{sp}^{3}\right)-\mathrm{H}$ bond in one of the mesityl substituents, as the molecular structure of $\mathbf{4}$ was confirmed by X-ray crystallographic analysis. The assignment of the $\mathrm{B} 2$ atom in the 2-boraindane skeleton could also be supported by the relatively long B2-C11 [1.626(4) $\AA$ ] and B2-C18 [1.591(4) $\AA$ ] bonds. In contrast, the reaction of 2 with an excess amount of ${ }^{t} \mathrm{BuNC}$ gave a mixture of ${ }^{t} \mathrm{BuNC}$-coordinated boraalkene 5 and borylethenylideneamine $\mathbf{6}$. The reaction with two equivalents of ${ }^{t} \mathrm{BuNC}$ in a diluted solution gave 5 as the major product, while the reaction with a large excess amount of ${ }^{t} \mathrm{BuNC}$ in a concentrated solution afforded $\mathbf{6}$ as the major product. X-ray crystallographic analysis of $\mathbf{5}$ and $\mathbf{6}$ revealed that these two compounds have similar arrangement of all atoms, except the order of the two atoms in the central $\mathrm{B}=\mathrm{C}$ or $\mathrm{C}-\mathrm{B}$ bond and the terminal $\mathrm{C}-\mathrm{N}-{ }^{t} \mathrm{Bu}$ angle $\left(5, \mathrm{~B} 2-\mathrm{C} 8-\mathrm{N} 2=173.6(2)^{\circ}\right.$; $\left.6, \mathrm{C} 2-\mathrm{N} 1-\mathrm{C} 3=131.7(4)^{\circ}\right)$. To form 5 , the $\mathrm{C} \equiv \mathrm{N}$ triple bond in ${ }^{t} \mathrm{BuNC}$, one B-B bond and two B-Mes bonds were cleaved from 2 , while the two mesityl groups are still attached to the boron atom in $\mathbf{6}$. In the molecular structure of $\mathbf{5}$, the boron centre has $\mathrm{B}=\mathrm{C}$ double-bond character $(\mathrm{B} 2-\mathrm{C} 7=1.456(3) \AA)$ and the second equivalent of ${ }^{t} \mathrm{BuNC}$ coordinates to the boron atom in the $\mathrm{B}=\mathrm{C}$ moiety. In the case of $\mathbf{6}$, the ${ }^{t} \mathrm{BuNC}$ moiety has consecutive $\mathrm{N}=\mathrm{C}$ and $\mathrm{C}=\mathrm{C}$ double bonds $(\mathrm{N} 1=\mathrm{C} 2=$ 1.217(5) $\AA, \quad C 2=\mathrm{C} 1=1.353(6) \AA)$ with a slightly short $\mathrm{C}-\mathrm{B}$ single bond $(\mathrm{C} 1-\mathrm{B} 1=1.516(7) \AA)$. All the obtained crystal structures could be reproduced by DFT calculation to support the assignment of atomic order (see below).

The NMR spectroscopic characterization of the products. The nuclear magnetic resonance (NMR) spectra of 3-5 were consistent with the crystallographically determined structures. The ${ }^{1} \mathrm{H}$ NMR spectrum of 3 in $\mathrm{C}_{6} \mathrm{D}_{6}$ showed two distinct Mes groups and one pinacol moiety. Two boron nuclei resonated at $\delta_{\mathrm{B}}-5$ and 18 p.p.m., where the former signal could be assigned as the COcoordinated boron atom due to the negatively charged boron atom in both the resonance structures $\mathbf{3}$ and $\mathbf{3}^{\prime}$. The calculated ${ }^{11} \mathrm{~B}$ NMR chemical shift $\left(\delta_{\mathrm{B}}-4.1,20\right.$ p.p.m.) of 3 by the Gaugeindependent atomic orbital (GIAO) method at B3LYP/6-311+ $+\mathrm{G}(2 \mathrm{~d}, \mathrm{p}) / / \mathrm{B} 3 \mathrm{LYP} / 6-31+\mathrm{G}(\mathrm{d}, \mathrm{p})$ level was also in good agreement with the experimental data (Supplementary Table 5). Although the two Mes groups and the pinacol moiety could be assigned in the ${ }^{13} \mathrm{C}$ NMR spectrum of 3 , no signal corresponding to $\mathrm{a} \mathrm{B}=\mathrm{C}$ unit and a coordinating $\mathrm{CO}$ molecule was observed. The ${ }^{1} \mathrm{H}$ NMR spectrum of $\mathbf{4}$ showed one benzylic methine proton $\left(\delta_{\mathrm{H}} 4.22\right)$ and two vicinally coupled methylene protons $\left(\delta_{\mathrm{H}} 2.87\right.$ and $2.93,{ }^{2} J_{\mathrm{HH}}=21 \mathrm{~Hz}$ ), supporting the scission of a $\mathrm{C}\left(s p^{3}\right)-\mathrm{H}$ bond in one of the two mesityl groups to give a chiral centre on C11. Reflecting the asymmetry below and above the 2-boraindane plane in 4 , all the remaining five methyl groups on the mesityl substituents were separately observed and the four methyl groups on the pinacolato moiety resonated two singlet signals. Both the boron nuclei in 4 resonated at a typical region for an $s p^{2}$ boron 
a

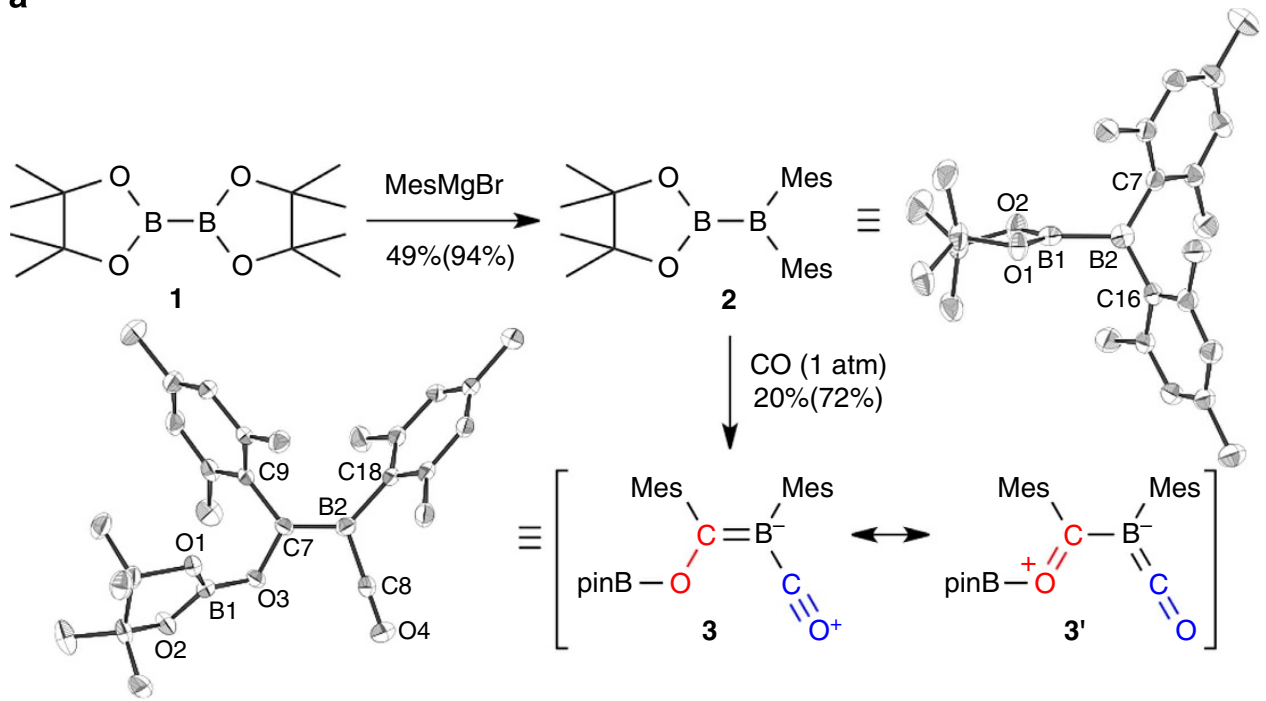

b

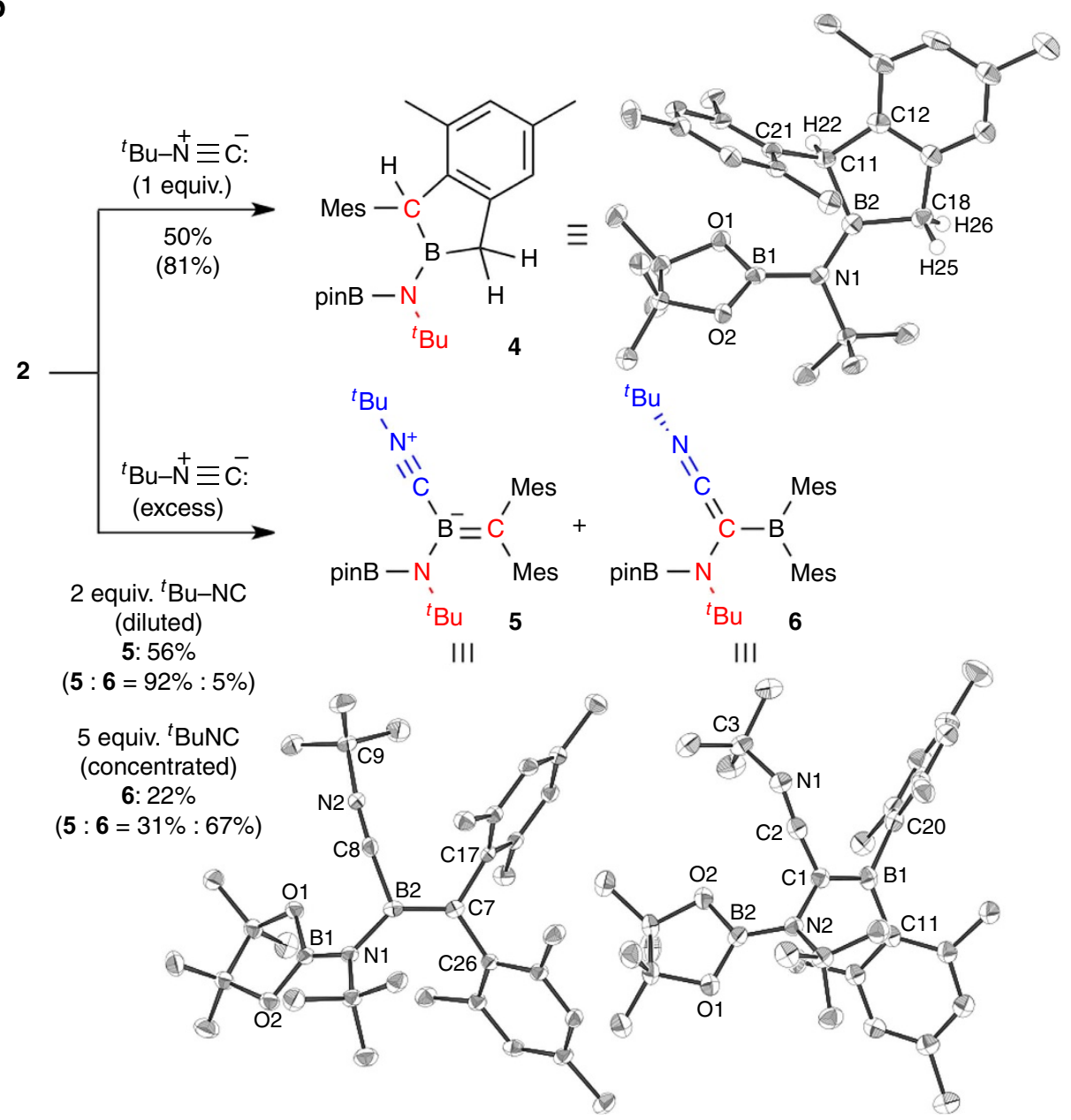

Figure 1 | Synthesis and reactions of unsymmetrical diborane(4) 2. (a) Synthesis and reaction of $\mathbf{2}$ with CO to form $\mathbf{3}$ and their crystal structures. (b) Reaction of $\mathbf{2}$ towards tert-butylisonitrile to form 4-6 and crystal structures of the products (isolated and ${ }^{1} \mathrm{H}$ NMR yield in parentheses, Mes $=2,4,6-$ $\left.\left(\mathrm{CH}_{3}\right)_{3} \mathrm{C}_{6} \mathrm{H}_{2}, \operatorname{pinB}=\left[\left(\mathrm{CH}_{3}\right)_{2} \mathrm{CO}\right]_{2} \mathrm{~B}\right)$ : Selected bond lengths $(\AA)$, bond angles $\left(^{\circ}\right)$ and dihedral angles $\left({ }^{\circ}\right) ; \mathbf{2}$ : $\mathrm{B} 1-\mathrm{B} 2=1.722(4) ; 3: \mathrm{B} 1-\mathrm{O} 1=1.366(3)$, $\mathrm{B} 1-\mathrm{O} 2=1.356(3), \mathrm{B} 1-\mathrm{O} 3=1.374(3), \mathrm{O} 3-\mathrm{C} 7=1.406(3), \mathrm{C} 7-\mathrm{B} 2=1.459(4), \mathrm{B} 2-\mathrm{C} 8=1.492(4), \mathrm{C} 8-\mathrm{O} 4=1.144(3) ; \mathbf{4}: \mathrm{B} 1-\mathrm{N} 1=1.455(3), \mathrm{N} 1-\mathrm{B} 2=1.415(3)$, $\mathrm{B} 2-\mathrm{C} 11=1.626(4), \mathrm{B} 2-\mathrm{C} 18=1.591(4) ; \mathbf{5}: \mathrm{B} 1-\mathrm{N} 1=1.413(3), \mathrm{N} 1-\mathrm{B} 2=1.495(3), \mathrm{B} 2-\mathrm{C} 7=1.456(3), \mathrm{B} 2-\mathrm{C} 8=1.569(3), \mathrm{C} 8-\mathrm{N} 2=1.152(3), \mathrm{B} 2-\mathrm{C} 8-$ $\mathrm{N} 2=173.6(2) ; 6: \mathrm{B} 1-\mathrm{C} 1=1.516(7), \mathrm{C} 1-\mathrm{C} 2=1.353(6), \mathrm{C} 2-\mathrm{N} 1=1.217(5), \mathrm{C} 1-\mathrm{N} 2=1.450(5), \mathrm{B} 2-\mathrm{N} 2=1.419(6), \mathrm{B} 1-\mathrm{C} 1-\mathrm{C} 2=114.8(4), \mathrm{C} 1-\mathrm{C} 2-\mathrm{N} 1=174.5(5)$, $\mathrm{C} 2-\mathrm{N} 1-\mathrm{C} 3=131.7(4)$. 
a

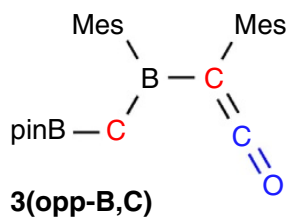

b

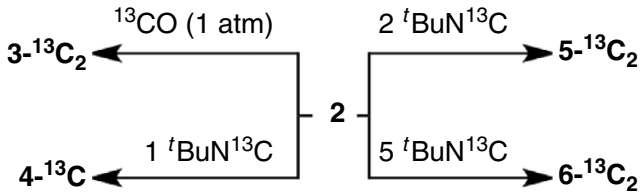

C d

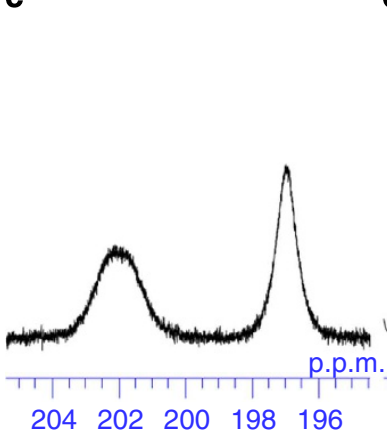

d

f

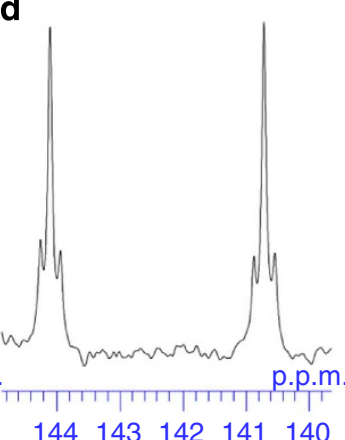

$144143 \quad 142 \quad 141 \quad 140 \quad 55$

g
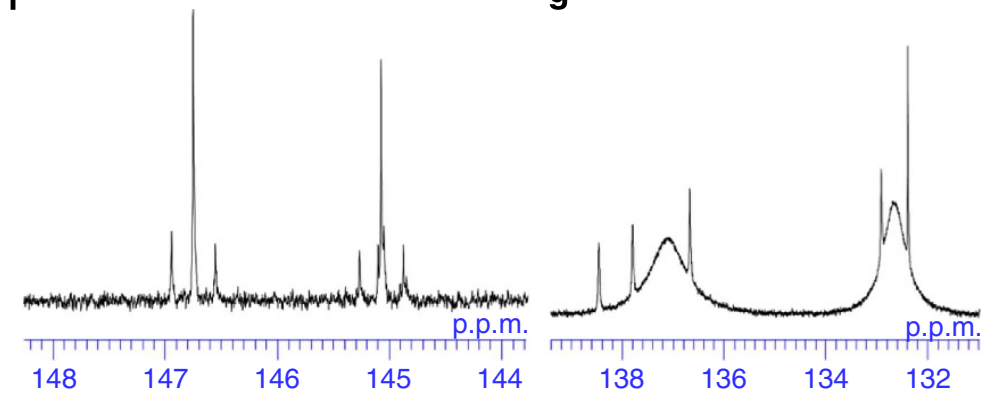

e

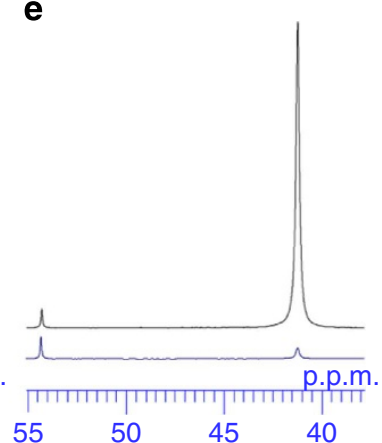

h

i

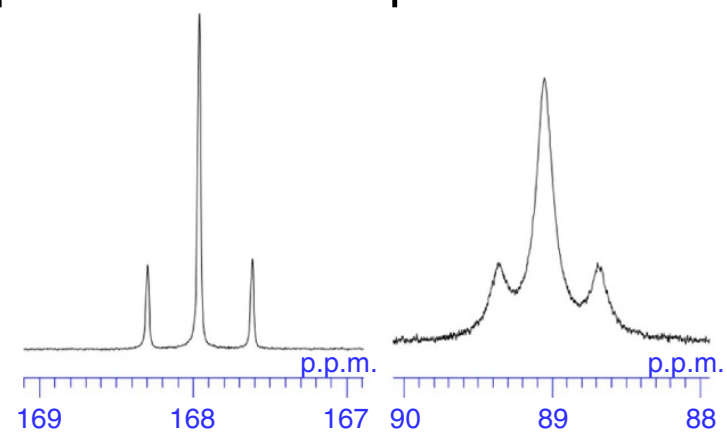

Figure 2 | Assignment of atomic order in 3-6 by ${ }^{13} \mathbf{C}$ NMR experiments with ${ }^{13} \mathbf{C}$ labelling. (a) Potential regioisomer 3(opp-B,C) derived from exchange of the positions of boron and carbon atoms in $\mathbf{3}$. (b) Reactions of $\mathbf{2}$ with ${ }^{13} \mathrm{C}$-labelled ${ }^{13} \mathrm{CO}$ and ${ }^{t} \mathrm{BuN}{ }^{13} \mathrm{C}$ to form the corresponding ${ }^{13} \mathrm{C}$-labelled

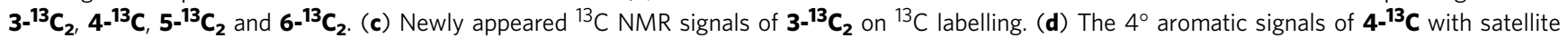
on ${ }^{13} \mathrm{C}$ labelling (e) enhancement of ${ }^{13} \mathrm{C}$ NMR signal (top: $\mathbf{4}^{\mathbf{1 3}} \mathbf{C}$, bottom: $\mathbf{4}$ ). (f) The $4^{\circ}$ aromatic signals of $\mathbf{5}^{{ }^{13}} \mathbf{C}_{\mathbf{2}}$ with satellite on ${ }^{13} \mathrm{C}$ labelling $(\mathbf{g}$ ) newly appeared ${ }^{13} \mathrm{C}$ NMR signals of $\mathbf{5}^{-13} \mathbf{C}_{\mathbf{2}}$ on ${ }^{13} \mathrm{C}$ labelling (h). (i) Strengthened ${ }^{13} \mathrm{C}$ NMR signals of $\mathbf{6}-\mathbf{1 3} \mathbf{C}_{\mathbf{2}}$ with satellite on ${ }^{13} \mathrm{C}$ labelling.

atom ( $\delta_{\mathrm{B}} 27,55$ p.p.m.). The lower-field shifted signal could be assigned as the dicarbyl-substituted boron atom as supported by our GIAO calculations. Two relatively broadened ${ }^{13} \mathrm{C}$ NMR signals at $\delta_{\mathrm{C}} 30.3$ and 41.2 p.p.m., compared with other signals of $\mathbf{4}$, supported their connection to quadrupolar boron nucleus. The ${ }^{1} \mathrm{H}$ NMR spectra of $\mathbf{5}$ and $\mathbf{6}$ similarly showed six methyl signals for the Mes groups, two methyl signals for the pinacol moiety, two ${ }^{t} \mathrm{Bu}$ signals and four aromatic $\mathrm{CH}$ signals, because they are regioisomers with the same combination of the substituents and are close in symmetry of molecule. In the ${ }^{13} \mathrm{C}$ NMR spectrum of 5 , the number of observed signals was two short of the number of
${ }^{13} \mathrm{C}$ nuclei expected from the symmetry of the ${ }^{1} \mathrm{H}$ NMR spectrum. Similarly, one carbon signal was missing in the ${ }^{13} \mathrm{C}$ NMR spectrum of 6 . The missing of the ${ }^{13} \mathrm{C}$ signals was probably due to broadening of quaternary carbon bonded to quadrupolar boron nucleus. The ${ }^{11} \mathrm{~B}$ NMR signals of $5\left(\delta_{\mathrm{B}} 13,21\right.$ p.p.m. $)$ and $6\left(\delta_{\mathrm{B}}\right.$ 21, 63 p.p.m.) could also be assigned by our GIAO calculations.

The ${ }^{13} \mathrm{C}$-labelling study to determine the atomic order. In addition to the conventional NMR spectra of $3-5,{ }^{13} \mathrm{C}$-labelling experiment could confirm the structures of 3-6 including 
connectivity between boron and carbon atoms (Fig. 2). Complete structural characterization of $\mathbf{3}, \mathbf{5}$ and $\mathbf{6}$ was difficult due to the following reasons: (1) in general, X-ray crystallographic analysis has difficulty to distinguish two adjacent atoms in the same row of the periodic table. This means that positions of carbon and boron atoms in 3 versus $3(\mathbf{o p p}-\mathbf{B}, \mathbf{C}$ ) (Fig. 2a) and 5 versus 6 could not be unambiguously determined by crystallography. (2) Both ${ }^{10} \mathrm{~B}$ and ${ }^{11} \mathrm{~B}$ nuclei are quadrupolar to induce significant broadening of the signal for boron-bonded nuclei, leading in difficulty for observation of quaternary carbon bonded to boron nucleus. In this context, we performed ${ }^{13} \mathrm{C}$-labelling experiments for 3-6 to observe the ${ }^{13} \mathrm{C}-{ }^{13} \mathrm{C}$ coupling and broadened ${ }^{13} \mathrm{C}$ NMR signals bonded to boron atom. The unsymmetrical diborane 2 reacted with ${ }^{13} \mathrm{C}$-labelled ${ }^{13} \mathrm{CO}\left(99 \%{ }^{13} \mathrm{C}\right)$ or ${ }^{t} \mathrm{BuN}^{13} \mathrm{C}(20 \%$
${ }^{13} \mathrm{C}$ ) gave ${ }^{13} \mathrm{C}$-labelled $3-{ }^{13} \mathrm{C}_{2}, 4-{ }^{13} \mathrm{C}, 5-{ }^{13} \mathrm{C}_{2}$ and $6-{ }^{13} \mathrm{C}_{2}$ (Fig. 2b). On ${ }^{13} \mathrm{C}$-labelling of 3 , two broad signals at $\delta_{\mathrm{C}} 197.1$ and 201.8 p.p.m. appeared without apparent coupling in the ${ }^{13} \mathrm{C}$ NMR spectrum of ${ }^{3-13} \mathrm{C}_{2}$ (Fig. 2c), indicating that these two carbon atoms connected to a quadrupolar boron atom with the $\mathrm{C}-\mathrm{B}=\mathrm{C}$ skeleton in $\mathbf{3}$ (not $\mathrm{C}-\mathrm{C}=\mathrm{B}$ in $\mathbf{3}(\mathbf{o p p}-\mathrm{B}, \mathrm{C})$ ). As described above, two broadened signals $\delta_{\mathrm{C}} 30.3$ and 41.2 p.p.m. may be assigned to the boron nucleus in 4 . The lower-field shifted signal at $\delta_{\mathrm{C}}$ 41.2 p.p.m. was strengthened on ${ }^{13} \mathrm{C}$ labelling to form $4^{-13} \mathrm{C}$ (Fig. 2e), indicating this benzylic methine carbon came from ${ }^{t} \mathrm{BuN}^{13} \mathrm{C}$. Concomitantly, two signals of aromatic quaternary carbons at $\delta_{\mathrm{C}} 140.7$ and 144.1 p.p.m. were accompanied with satellite signal with ${ }^{1} J_{\mathrm{CC}}$ of $40 \mathrm{~Hz}$ (Fig. 2 d), similar to that $(43 \mathrm{~Hz})$ for the $\mathrm{C}\left(s p^{2}\right)-\mathrm{C}\left(s p^{3}\right)$ linkage in strychnine ${ }^{64}$, indicating that the

a

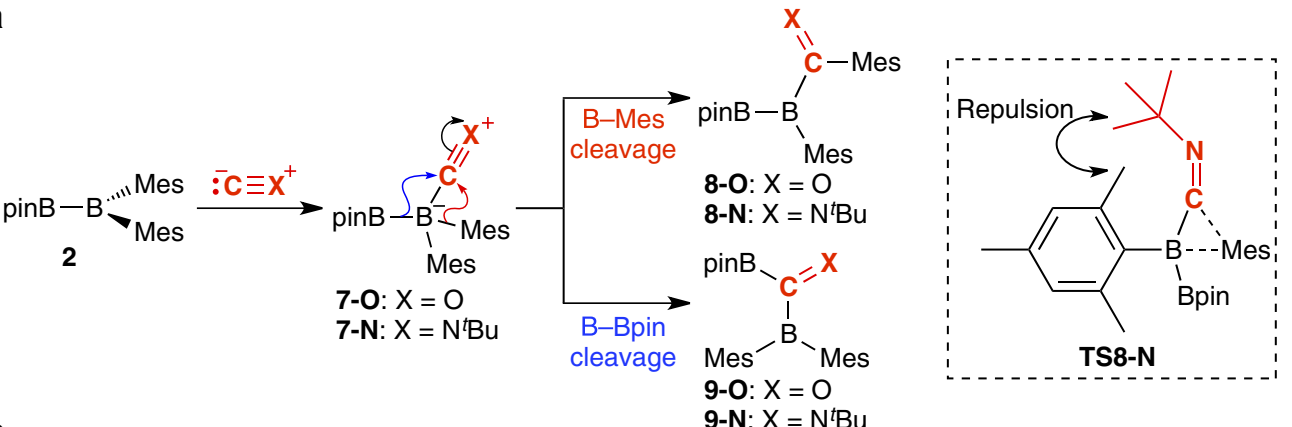

b

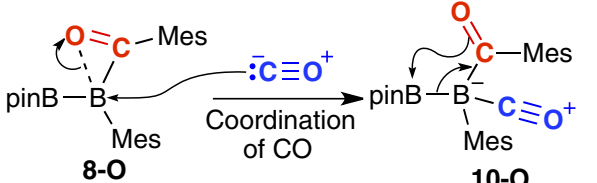

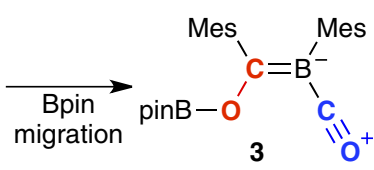
$\overline{: C} \equiv \mathrm{O}^{+} \uparrow \begin{aligned} & \text { Coordination } \\ & \text { of } \mathrm{CO}\end{aligned}$<smiles>CCC1C[C@H]2CC[C@@H]1C(=O)B2OC</smiles>

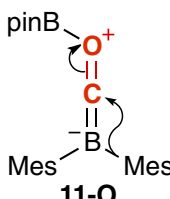

-O (1) 
two ipso carbons of the two Mes groups bonded to the $s p^{3}$ methine ${ }^{13} \mathrm{C}$ are from ${ }^{t} \mathrm{BuN}^{13} \mathrm{C}$. In the case of $5^{-13} \mathrm{C}_{2}$, two broad signals appeared at $\delta_{\mathrm{C}} 132.7$ and 137.1 p.p.m. on labelling (Fig. 2g), supporting the $\mathrm{C}-\mathrm{B}=\mathrm{C}$ skeleton of 5 . Two split $4^{\circ}$ aromatic signals with ${ }^{1} J_{\mathrm{CC}}$ of $24 \mathrm{~Hz}$ in ${ }^{5-}{ }^{13} \mathrm{C}_{2}$ also showed that the two Mes groups bonds to a carbon atom (Fig. 2f). The ${ }^{13} \mathrm{C}$ NMR spectrum of $\mathbf{6}^{13} \mathrm{C}_{2}$ showed two strengthened signals at $\delta_{\mathrm{C}} 89.1$ and 168.0 p.p.m. (Fig. 2h,i) with a satellite $\left({ }^{1} J_{\mathrm{CC}}=86 \mathrm{~Hz}\right)$, supporting the $\mathrm{C}\left(s p^{2}\right)-\mathrm{C}(s p)$ coupling $(107 \mathrm{~Hz}$ in diphenylketene- $\left.{ }^{13} \mathrm{C}_{2}\right){ }^{65}$. One can confirm that the carbon atom with the $\delta_{\mathrm{C}} 89.1$ p.p.m. signal is bonded to a quadrupolar boron atom in the structure of $\mathbf{6}$, according to the broadening observed.

Proposed mechanism based on DFT calculation. The whole mechanisms for the formation of 3-6 from $\mathbf{2}$ were estimated by DFT calculations ${ }^{66-69}$ with full geometry optimization of all the available transition states (TSs) at the B3LYP/6-31G(d,p) level and single-point energy calculation at M06-2X/6-311+G(d,p) with solvent effect of benzene using conductor-like polarizable continuum model (Fig. 3: mechanism with curly arrows, Fig. 4: energy profiles with relative Gibbs free energies and Supplementary Table 6 for coordinates of all the structures). An initial coordination of $\mathrm{CO}$ or ${ }^{t} \mathrm{BuNC}$ to 2 gave the $s p^{2}-s p^{3}$ diborane(4) 7-O and 7-N, which would undergo two types of bond cleavage reactions (Fig. 3a): (1) B-Mes bond cleavage to give acyldiborane(4) 8-O or imidoyldiborane(4) 8-N, (2) B-Bpin bond cleavage to give diborylketone $\mathbf{9 - O}$ or diborylimine $\mathbf{9 - N}$. In the reaction of $\mathbf{2}$ with CO, energy levels of TS8-O and TS9-O are comparable to each other and both TSs are higher than the TS7O (Fig. 4a). The slightly lower TS8-O could be explained by the higher nucleophilicity of a Mes substituent than a Bpin substituent due to the electronegativity difference between carbon and boron atoms, as supported by natural bond orbital
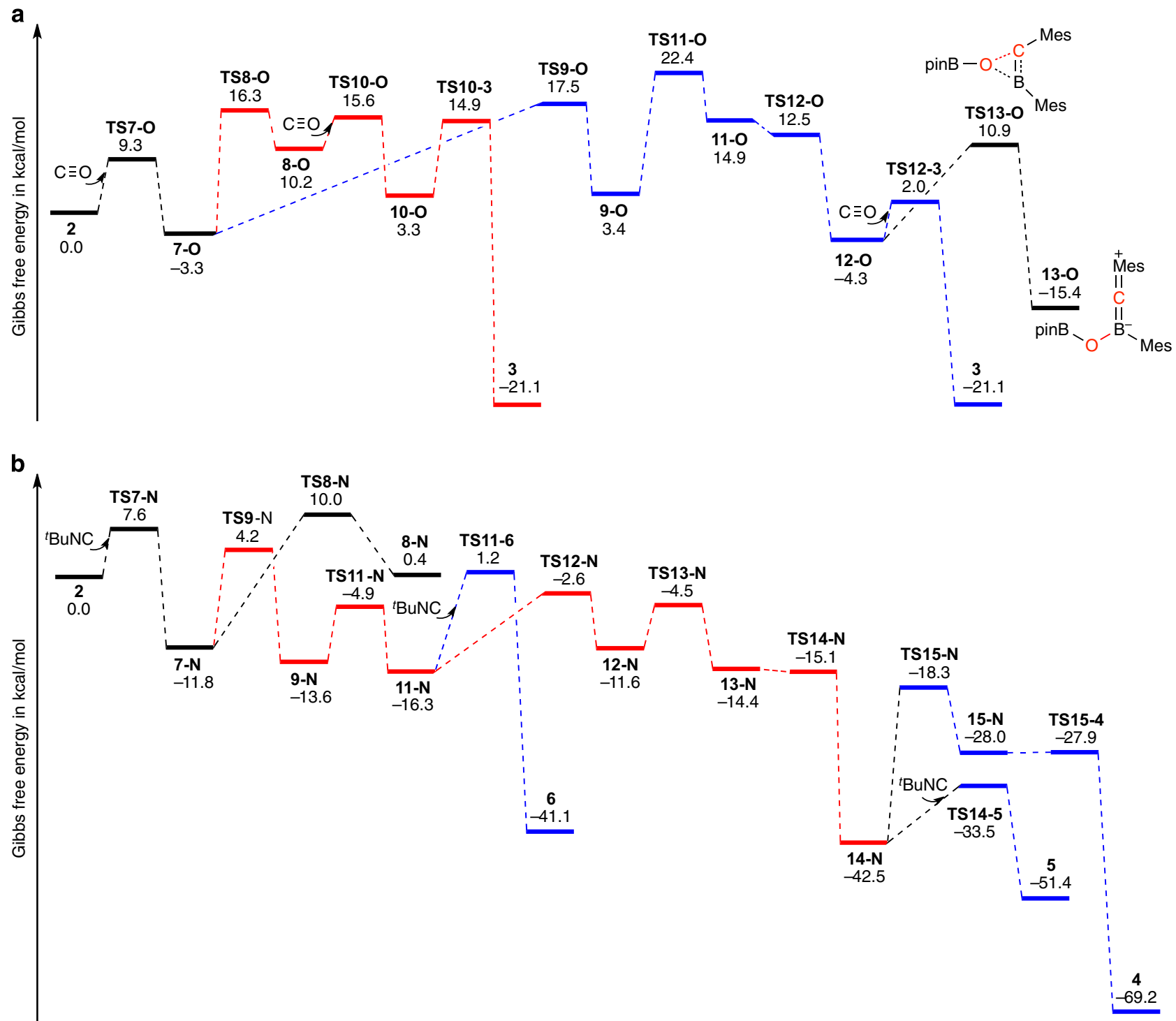

Figure 4 | Energy profiles of possible mechanism. Energy profiles of possible mechanism for the formation of 3-6 from $\mathbf{2}$ with relative Gibbs free energies in $\mathrm{kcal} \mathrm{mol}^{-1}$ (estimated by optimization at the B3LYP/6-31G(d,p) level and subsequent single-point energy calculation at M06-2X/6-311 + G(d,p) level with consideration of entropy contribution and solvent effect of benzene (conductor-like polarizable continuum model (CPCM)), all the compound numbers are in conjunction with Fig. 3). (a) Two possible pathways for the formation of $\mathbf{3}$ by reaction of $\mathbf{2}$ with CO (red: pathway through 8-0, blue: pathway through 9-0) (b) pathway for the formation of 4-6 by reaction of $\mathbf{2}$ with ${ }^{t} \mathrm{BuNC}$ (red: main pathway to 4-6, blue: branching to each of the compounds 4-6). (Remark: before the solvation correction, TS12-0 is slightly higher than 11-0 and TS14-N is slightly higher than $\mathbf{1 3 - N}$ in energy.) 
analysis (Supplementary Fig. 20). The subsequent reactions from 8-O and 9-O afforded the same product $\mathbf{3}$ (Fig. $3 \mathrm{~b}$ ). The former pathway through 8-O included a coordination of a second $\mathrm{CO}$ molecule to give 10-O and subsequent migration of the Bpin moiety by a nucleophilic attack of the acyl oxygen atom in 10-O with $\mathrm{B}-\mathrm{B}$ bond cleavage to give 3 . The large energy gain in this step may be attributed to the formation of $\mathrm{B}-\mathrm{O}$ bond. The latter pathway through 9-O was initiated by a Bpin migration to form the borataalkene 11-O. TS11-O was the global TS, which lies $6.1 \mathrm{kcal} \mathrm{mol}^{-1}$ higher than TS8-O. Subsequently, one of the two Mes groups in 11-O migrated to the carbon atom to afford the boraalkene 12-O. Coordination of a second $\mathrm{CO}$ molecule to 12-O could form the same product 3 . This step could be considered as a coordination of $\mathrm{CO}$ to electron-deficient boraalkene for a large energy gain. Formation of a possible $\mathrm{C}-\mathrm{O}$ cleaved product 13-O would be suppressed due to the higher TS13-O (Fig. 4a).

In the reaction of 2 with ${ }^{t} \mathrm{BuNC}$, TS8-N was $5.8 \mathrm{kcal} \mathrm{mol}^{-1}$ higher than TS9-N, indicating that the pathway through 9-N would be favourable (Fig. 4a). The high energy level of TS8-N may be explained by a steric repulsion between the spectator Mes group and the ${ }^{t} \mathrm{Bu}$ group (Fig. 3a and Supplementary Table 7). The intermediate 9-N would undergo Bpin migration to give 11$\mathbf{N}$ followed by a Mes group migration to form the boraalkene 12$\mathbf{N}$ (Fig. 3c). Coordination of ${ }^{t} \mathrm{BuNC}$ to the central carbon atom in 11-N could lead to formation of $\mathbf{6}$, but the TS to $\mathbf{6}$ was calculated to be slightly higher (by $3.8 \mathrm{kcal} \mathrm{mol}^{-1}$ ) than the TS to $12-\mathrm{N}$. Requirement of higher concentration to prepare $\mathbf{6}$ was consistent with this result. Again, the simple coordination of ${ }^{t} \mathrm{BuNC}$ to boraalkene would give a large energy gain. As a nitrogen atom in 12-N may have higher nucleophilicity than the oxygen atom in 12-O, a migration of the amino substituent $\left(-\mathrm{N}^{t} \mathrm{BuBpin}\right)$ to the Mes-bonded boron atom would take place with an assistance of electron donation from the carbon-bonded Mes group to form the amino-substituted borataalkene 13-N. This step (from 12-N to 13-N) involves a cleavage of the $\mathrm{C}-\mathrm{N}$ bond originated from the $\mathrm{C} \equiv \mathrm{N}$ triple bond in ${ }^{t} \mathrm{BuNC}$. Electron donation from the nitrogen atom to the boron atom in 13- $\mathbf{N}$ induced the second Mes migration to the carbon atom to give the aminoboraalkene 14-N. The neutralization of the positively charged Mes group may contribute a large energy gain. A simple coordination of a second ${ }^{t} \mathrm{BuNC}$ molecule to $\mathbf{1 4}$-N affords the product $\mathbf{5}$. This result is consistent with the experimental observation that when ${ }^{t} \mathrm{BuNC}$ is in excess the product 5 was obtained. In the absence of excess ${ }^{t} \mathrm{BuNC}$, the boron centre of $\mathbf{1 4 - N}$ would attack to one of the benzylic protons to give the cyclic hydroborate 15-N having delocalized cationic charge on the cyclized Mes ring, as a boryl anion could undergo the same deprotonation cyclization ${ }^{70}$. The energy barrier of $24.2 \mathrm{kcal} \mathrm{mol}^{-1}$ from 14-N to TS15-N is accessible at the room temperature (the reaction condition). Subsequent 1,2-hydride shift from $\mathbf{1 5}-\mathbf{N}$ and re-aromatization would form the product 4 . The formation of $\mathrm{B}-\mathrm{N} \pi$-bond in the last step would contribute a large energy gain.

\section{Discussion}

Thus, the detailed spectroscopic and structural analysis of the obtained products and the DFT calculations revealed the complexity of the consecutive rearrangement reactions of $\mathbf{2}$. The reason why the newly synthesized diborane(4) 2 showed a remarkable reactivity towards $\mathrm{CO}$ and ${ }^{t} \mathrm{BuNC}$ in comparison with the conventional boron-containing compounds may be attributed to the existence of two reactive $\mathrm{B}-\mathrm{C}$ bonds and one reactive $\mathrm{B}-\mathrm{B}$ bond. Throughout the reactions, the boron atoms in the intermediates undergo repetitive interconversion between $s p^{2}$ and $s p^{3}$ states to induce the subsequent reactions. In the case of ${ }^{t} \mathrm{BuNC}$, the intermediate $\mathbf{1 2}-\mathbf{N}$, which is derived after the two $\pi$-bonds of the isonitrile moiety have been cleaved, contains a single C-N $\sigma$-bond and has a highly nucleophilic nitrogen atom. The highly nucleophilic nitrogen atom facilitates further cleavage of the remaining $\sigma$-bond through migrating to the adjacent unsaturated boron centre. Coexistence of the reactive B-B and B$\mathrm{C}$ bonds, steric crowdedness in $\mathbf{2}$ and the high nucleophilicity of $\mathrm{N}$ in 12-N containing a single $\mathrm{C}-\mathrm{N} \sigma$-bond cooperatively achieved the complete cleavage of the $\mathrm{C} \equiv \mathrm{N}$ triple bond. In conclusion, we demonstrated the first example of $\mathrm{C} \equiv \mathrm{N}$ triple bond cleavage by using newly synthesized diborane(4) 2 in the absence of TM reagents and catalysts. The present results may inspire new idea to achieve multiple bond cleavage reactions using main group element compounds.

\section{References}

1. Fürstner, A. Alkyne Metathesis on the Rise. Angew. Chem. Int. Ed. 52, 2794-2819 (2013).

2. Sullivan, B. P., Smythe, R. S., Kober, E. M. \& Meyer, T. J. Cleavage of the triple bond in phenylacetylene by monomeric ruthenium(II) and osmium(II) complexes. Formation of stable ruthenium(II) alkyls from terminal alkynes. J. Am. Chem. Soc. 104, 4701-4703 (1982).

3. O'Connor, J. M. \& Pu, L. Surreptitious involvement of a metallacycle substituent in metal-mediated alkyne cleavage chemistry. J. Am. Chem. Soc. 112, 9013-9015 (1990).

4. Cairns, G. A., Carr, N., Green, M. \& Mahon, M. F. Reaction of $\left[\mathrm{W}\left(\eta^{2}\right.\right.$ $\left.\left.\mathrm{PhC}_{2} \mathrm{Ph}\right)_{3}(\mathrm{NCMe})\right]$ with $o$-diphenylphosphino-styrene and -allylbenzene; evidence for novel carbon-carbon double and triple bond cleavage and alkyne insertion reactions. Chem. Commun. 2431-2432 (1996).

5. Hayashi, N., Ho, D. M. \& Pascal, Jr R. A. An unusual cobalt-mediated cleavage of a hindered alkyne. Tetrahedron Lett. 41, 4261-4264 (2000).

6. Jun, C. -H., Lee, H., Moon, C. W. \& Hong, H. -S. Cleavage of carbon-carbon triple bond of alkyne via hydroiminoacylation by $\mathrm{Rh}(\mathrm{I})$ catalyst. J. Am. Chem. Soc. 123, 8600-8601 (2001).

7. Lee, D. -Y., Hong, B. -S., Cho, E. -G., Lee, H. \& Jun, C. -H. A hydroacylationtriggered carbon-carbon triple bond cleavage in alkynes via retro-Mannich type fragmentation. J. Am. Chem. Soc. 125, 6372-6373 (2003).

8. Datta, S., Chang, C.-L., Yeh, K.-L. \& Liu, R.-S. A new ruthenium-catalyzed cleavage of a carbon-carbon triple bond: efficient transformation of ethynyl alcohol into alkene and carbon monoxide. J. Am. Chem. Soc. 125, 9294-9295 (2003).

9. Liu, Y., Song, F. \& Guo, S. Cleavage of a carbon-carbon triple bond via goldcatalyzed cascade cyclization/oxidative cleavage reactions of (Z)-enynols with molecular oxygen. J. Am. Chem. Soc. 128, 11332-11333 (2006).

10. Wang, A. \& Jiang, H. Palladium-catalyzed cleavage reaction of carbon-carbon triple bond with molecular oxygen promoted by Lewis acid. J. Am. Chem. Soc. 130, 5030-5031 (2008).

11. Shen, T., Wang, T., Qin, C. \& Jiao, N. Silver-catalyzed nitrogenation of alkynes a direct approach to nitriles through $\mathrm{C} \equiv \mathrm{C}$ bond cleavage. Angew. Chem. Int. Ed. 52, 6677-6680 (2013).

12. Roy, S. et al. Dissecting alkynes: full cleavage of polarized $\mathrm{C} \equiv \mathrm{C}$ moiety via sequential bis-michael addition/retro-Mannich cascade. J. Org. Chem. 76, 7482-7490 (2011).

13. Okamoto, N., Ishikura, M. \& Yanada, R. Cleavage of carbon-carbon triple bond: direct transformation of alkynes to nitriles. Org. Lett. 15, 2571-2573 (2013).

14. Griesbaum, K. et al. in: Ullmann's Encyclopedia of Industrial Chemistry (WileyVCH Verlag GmbH \& Co. KGaA, 2000).

15. Yandulov, D. V. \& Schrock, R. R. Catalytic reduction of dinitrogen to ammonia at a single molybdenum center. Science 301, 76-78 (2003).

16. Arashiba, K., Miyake, Y. \& Nishibayashi, Y. A molybdenum complex bearing PNP-type pincer ligands leads to the catalytic reduction of dinitrogen into ammonia. Nat. Chem. 3, 120-125 (2011).

17. Anderson, J. S., Rittle, J. \& Peters, J. C. Catalytic conversion of nitrogen to ammonia by an iron model complex. Nature 501, 84-87 (2013).

18. Sun, X., Wang, C., Li, Z., Zhang, S. \& Xi, Z. Zirconocene-mediated intermolecular coupling of one molecule of si-tethered diyne with three molecules of organonitriles: one-pot formation of pyrrolo[3,2-c]pyridine derivatives via cleavage of $\mathrm{C} \equiv \mathrm{N}$ triple bonds of organonitriles. J. Am. Chem. Soc. 126, 7172-7173 (2004).

19. Tanabe, Y., Seino, H., Ishii, Y. \& Hidai, M. Reaction mechanism of the C $\equiv N$ triple bond cleavage of $\beta$-ketonitriles on a molybdenum( 0 ) center. J. Am. Chem. Soc. 122, 1690-1699 (2000).

20. Kawashima, T., Takao, T. \& Suzuki, H. Cleavage of the $\mathrm{C} \equiv \mathrm{N}$ bond on a triruthenium cluster: synthesis and structure of a triruthenium complex containing a $\mu^{3}$-nitrido ligand. Angew. Chem. Int. Ed. 45, 485-488 (2006). 
21. Geyer, A. M. et al. Synthetic, mechanistic, and computational investigations of nitrile-alkyne cross-metathesis. J. Am. Chem. Soc. 130, 8984-8999 (2008).

22. Boyd, J. P., Schlangen, M., Grohmann, A. \& Schwarz, H. Room-temperature alkyne-nitrile metathesis and unambiguous proof for the existence of a highvalent iron-nitrido dication in the gas phase. Helv. Chim. Acta 91, 1430-1434 (2008).

23. Wiedner, E. S., Gallagher, K. J., Johnson, M. J. A. \& Kampf, J. W. Synthesis of molybdenum nitrido complexes for triple-bond metathesis of alkynes and nitriles. Inorg. Chem. 50, 5936-5945 (2011).

24. Sprangers, W. J. J. M. \& Louw, R. Carbonylation of organomagnesium compounds: catalysis by hexamethylphosphoric triamide. J. Chem. Soc. Parkin Trans. 2, 1895-1901 (1976).

25. Seyferth, D. \& Weinstein, R. M. High-yield acyl-anion trapping reactions: a synthesis of acyltrimethylsilanes. J. Am. Chem. Soc. 104, 5534-5535 (1982).

26. Brown, H. C. Organoborane-carbon monoxide reactions. Synthesis of carbon structures. Acc. Chem. Res. 2, 65-72 (1969).

27. Paetzold, P., Redenz-Stormanns, B. \& Boese, R. Boroboration of CO with Tri-tert-butylazadiboriridine. Angew. Chem. Int. Ed. Engl. 29, 900-902 (1990).

28. Teichmann, J., Stock, H., Pritzkow, H. \& Siebert, W. Carbon monoxide and isonitrile insertion into the $\mathrm{B}-\mathrm{B}$ bond of five-membered cyclic organo-1,2diboranes. Eur. J. Inorg. Chem. 1998, 459-463 (1998).

29. Mason, M. R., Song, B. \& Kirschbaum, K. Remarkable room-temperature insertion of carbon monoxide into an aluminum - carbon bond of tri-tertbutylaluminum. J. Am. Chem. Soc. 126, 11812-11813 (2004).

30. Li, X., Ni, C., Song, H. \& Cui, C. Formation of aluminacyclobutenes via carbon monoxide and isocyanide insertion. Chem. Commun. 1763-1765 (2006).

31. Mason, M. R., Song, B., Han, Y. \& Hu, X. Reaction of carbon monoxide with tri-tert-butylgallium:the first example of $\mathrm{CO}$ insertion into a gallium-carbon bond. Inorg. Chim. Acta 361, 3332-3337 (2008).

32. Lavallo, V., Canac, Y., Donnadieu, B., Schoeller, W. W. \& Bertrand, G. CO fixation to stable acyclic and cyclic alkyl amino carbenes: stable amino ketenes with a small HOMO-LUMO gap. Angew. Chem. Int. Ed. 45, 3488-3491 (2006).

33. Sajid, M. et al. Facile carbon monoxide reduction at intramolecular frustrated phosphane/borane lewis pair templates. Angew. Chem. Int. Ed. 52, 2243-2246 (2013).

34. Dobrovetsky, R. \& Stephan, D. W. Stoichiometric metal-free reduction of CO in syn-gas. J. Am. Chem. Soc. 135, 4974-4977 (2013).

35. Braunschweig, H. et al. Metal-free binding and coupling of carbon monoxide at a boron-boron triple bond. Nat. Chem. 5, 1025-1028 (2013).

36. Nakata, N., Oikawa, T., Matsumoto, T., Kabe, Y. \& Sekiguchi, A. Silylsubstituted 1,4-disila(dewar benzene): new synthesis and unexpected insertion of $\mathrm{CO}$ into the $\mathrm{Si}-\mathrm{Si}$ bond to form a disilyl ketone. Organometallics $\mathbf{2 4}$, 3368-3370 (2005).

37. Wang, X. et al. Room-temperature reaction of carbon monoxide with a stable diarylgermylene. J. Am. Chem. Soc. 131, 6912-6913 (2009).

38. Brown, Z. D. \& Power, P. P. Mechanisms of reactions of open-shell, heavier group 14 derivatives with small molecules: $\mathrm{n}-\pi^{*}$ back-bonding in isocyanide complexes, $\mathrm{C}-\mathrm{H}$ activation under ambient conditions, $\mathrm{CO}$ coupling, and ancillary molecular interactions. Inorg. Chem. 52, 6248-6259 (2013).

39. Luckert, S. et al. Tri-tert-butylazadiboriridin: ringerweiterung mit isonitrilen, $\alpha$-bromlithioalkanen und aziden. Chem. Ber. 128, 1029-1035 (1995).

40. Bauer, F., Braunschweig, H. \& Schwab, K. 1,1-diboration of isocyanides with [2]borametalloarenophanes. Organometallics 29, 934-938 (2010).

41. Nguyen, P. et al. Lewis base adducts of diboron compounds: molecular structures of $\left[\mathrm{B}_{2}(\mathrm{cat})_{2}\right.$ (4-picoline) $]$ and $\left[\mathrm{B}_{2}(\mathrm{cat})_{2}(4 \text {-picoline })_{2}\right]$ (cat $=1,2$ $\mathrm{O}_{2} \mathrm{C}_{6} \mathrm{H}_{4}$ ). Inorg. Chem. 34, 4290-4291 (1995).

42. Clegg, W. et al. Lewis-base adducts of the diborane(4) compounds $\mathrm{B}_{2}(1,2-$ $\left.\mathrm{E}_{2} \mathrm{C}_{6} \mathrm{H}_{4}\right)_{2}(\mathrm{E}=\mathrm{O}$ or S). J. Chem. Soc. Dalton 839-846 (1997).

43. Grigsby, W. J. \& Power, P. P. One-electron reductions of organodiborane(4) compounds: Singly reduced anions and rearrangement reactions. Chem. Eur. J. 3, 368-375 (1997).

44. Neu, A. et al. Novel tetraalkyltetraboranes of the type $\mathrm{B}_{4} \mathrm{R}_{4}, \mathrm{~B}_{4} \mathrm{H}_{2} \mathrm{R}_{4}$ and $\mathrm{B}_{4} \mathrm{H}_{4} \mathrm{R}_{4}$. Inorg. Chim. Acta 289, 58-69 (1999).

45. Clegg, W., Marder, T. B., Nlate, S. \& Scott, A. J. 2,3,5,6-Tetrakis[3,5bis(trifluoromethyl)phenoxy]-2,5-bis(dimethylamino)2,3,5,6-tetrabora-1,4dioxane diethyl ether 0.667-solvate. Act. Cryst. Sec. C 63, O603-O605 (2007).

46. Gao, M., Thorpe, S. B. \& Santos, W. L. $\mathrm{sp}^{2}-\mathrm{sp}^{3}$ hybridized mixed diboron: synthesis, characterization, and copper-catalyzed $\beta$-boration of $\alpha, \beta$-unsaturated conjugated compounds. Org. Lett. 11, 3478-3481 (2009).

47. Gao, M. et al. Structure and reactivity of a preactivated $\mathrm{sp}^{2}-\mathrm{sp}^{3}$ diboron reagent: catalytic regioselective boration of $\alpha, \beta$-unsaturated conjugated compounds. J. Org. Chem. 76, 3997-4007 (2011).

48. Thorpe, S. B., Guo, X. \& Santos, W. L. Regio- and stereoselective coppercatalyzed $\beta$-borylation of allenoates by a preactivated diboron. Chem. Commun. 47, 424-426 (2011).
49. Nozaki, K. et al. Boryltrihydroborate: synthesis, structure, and reactivity as a reductant in ionic, organometallic, and radical reactions. J. Am. Chem. Soc. 132, 11449-11451 (2010).

50. Bissinger, P. et al. Generation of a carbene-stabilized bora-borylene and its insertion into a C-H bond. J. Am. Chem. Soc. 133, 19044-19047 (2011).

51. Braunschweig, H., Damme, A., Jimenez-Halla, J. O. C., Kupfer, T. \& Radacki, K. Phosphine adducts of 1,2-dibromo-1,2-dimesityldiborane(4): between bridging halides and rearrangement processes. Angew. Chem. Int. Ed. 51, 6267-6271 (2012).

52. Braunschweig, H. et al. Quaternizing diboranes(4): highly divergent outcomes and an inorganic Wagner-Meerwein rearrangement. J. Am. Chem. Soc. 135, 8702-8707 (2013).

53. Braunschweig, H., Damme, A. \& Kupfer, T. Synthesis of a bicyclic diborane by selective boron carbon bond formation. Chem. Commun. 49, 2774-2776 (2013).

54. Bonet, A., Gulyás, H. \& Fernández, E. Metal-free catalytic boration at the $\beta$-position of $\alpha, \beta$-unsaturated compounds: a challenging asymmetric induction. Angew. Chem. Int. Ed. 49, 5130-5134 (2010).

55. Bonet, A., Pubill-Ulldemolins, C., Bo, C., Gulyás, H. \& Fernández, E. Transition-metal-free diboration reaction by activation of diboron compounds with simple Lewis bases. Angew. Chem. Int. Ed. 50, 7158-7161 (2011).

56. Pubill-Ulldemolins, C., Bonet, A., Bo, C., Gulyás, H. \& Fernández, E. Activation of diboron reagents with Brønsted bases and alcohols: an experimental and theoretical perspective of the organocatalytic boron conjugate addition reaction. Chem. Eur. J. 18, 1121-1126 (2012).

57. Pubill-Ulldemolins, C., Bonet, A., Gulyas, H., Bo, C. \& Fernandez, E. Essential role of phosphines in organocatalytic $\beta$-boration reaction. Org. Biomol. Chem. 10, 9677-9682 (2012).

58. Sanz, X. et al. Metal-free borylative ring-opening of vinyl epoxides and aziridines. Org. Biomol. Chem. 11, 7004-7010 (2013).

59. Lee, K.-s., Zhugralin, A. R. \& Hoveyda, A. H. Efficient C - B bond formation promoted by $\mathrm{N}$-heterocyclic carbenes: synthesis of tertiary and quaternary B-substituted carbons through metal-free catalytic boron conjugate additions to cyclic and acyclic $\alpha, \beta$-unsaturated carbonyls. J. Am. Chem. Soc. 131, 7253-7255 (2009).

60. Wu, H., Radomkit, S., O’Brien, J. M. \& Hoveyda, A. H. Metal-free catalytic enantioselective $\mathrm{C}-\mathrm{B}$ bond formation: (pinacolato)boron conjugate additions to $\alpha, \beta$-unsaturated ketones, esters, Weinreb amides, and aldehydes promoted by chiral N-heterocyclic carbenes. J. Am. Chem. Soc. 134, 8277-8285 (2012).

61. Cid, J., Carbó, J. J. \& Fernández, E. A clear-cut example of selective Bpin-Bdan activation and precise Bdan transfer on boron conjugate addition. Chem. Eur. J. 20, 3616-3620 (2014).

62. Nöth, H. Contributions to the chemistry of boron, 153. The crystal and molecular-structure of a 1.3.2-dioxaborolan-2-yl-1',3',2'-dioxaborolane. $Z$. Naturforsch. B Chem. Sci. 39, 1463-1466 (1984).

63. Lide, D. R. (ed) CRC Handbook of Chemistry and Physics (CRC Press, 2012).

64. Williamson, R. T., Buevich, A. V. \& Martin, G. E. Experimental and theoretical investigation of 1JCC and nJCC coupling constants in strychnine. Org. Lett. 14, 5098-5101 (2012).

65. Anderson, J. C. \& Broughton, S. Efficient synthesis of diphenylketene- ${ }^{13} \mathrm{C}_{2}$. Synthesis 2001, 2379-2380 (2001).

66. Becke, A. D. Density-functional exchange-energy approximation with correct asymptotic behavior. Phys. Rev. A 38, 3098-3100 (1988).

67. Lee, C., Yang, W. \& Parr, R. G. Development of the Colle-Salvetti correlationenergy formula into a functional of the electron density. Phys. Rev. B 37, 785-789 (1988).

68. Zhao, Y. \& Truhlar, D. G. The M06 suite of density functionals for main group thermochemistry, thermochemical kinetics, noncovalent interactions, excited states, and transition elements: two new functionals and systematic testing of four M06-class functionals and 12 other functionals. Theor. Chem. Acc. 120, 215-241 (2008).

69. Cossi, M., Barone, V., Mennucci, B. \& Tomasi, J. Ab initio study of ionic solutions by a polarizable continuum dielectric model. Chem. Phys. Lett. 286, 253-260 (1998).

70. Segawa, Y., Suzuki, Y., Yamashita, M. \& Nozaki, K. Chemistry of boryllithium: synthesis, structure, and reactivity. J. Am. Chem. Soc. 130, 16069-16079 (2008).

\section{Acknowledgements}

We thank Professor Hiyama T. of Research and Development Initiative, Chuo University, for providing X-ray diffractometer and Professor Sasamori T. of Kyoto University for fruitful discussion about analysing crystal structure. This research was supported by Grants-in-Aid for Scientific Research on Innovative Areas ('Stimulusresponsible Chemical Species for Creation of Functional Molecules' (24109012 to M.Y.)) from MEXT, The Science Research Promotion Fund from The Promotion and 
Mutual Aid Corporation for Private Schools of Japan (M.Y.) and the Research Grants Council of Hong Kong (HKUST 603313 and CUHK7/CRF/12G) (Z.L.). Part of the computations was performed using Research Center for Computational Science, Okazaki, Japan.

\section{Author contributions}

M.Y. and Z.L. designed the study. H.A. conducted all the experiments and part of DFT calculations. H.A. and M.Y. analysed crystal structures. K.H.L. and Z.L. performed mechanistic study. Z.L. and M.Y. wrote the manuscript

\section{Additional information}

Accession codes. The X-ray crystal structure information is available at the Cambridge Crystallographic Data Centre (CCDC) under deposition numbers CCDC985350 (1), CCDC-981112 (2), CCDC-981113 (3), CCDC-981114 (4), CCDC-981115 (5) and CCDC-985351 (6). These data can be obtained free of charge from The Cambridge Crystallographic Data Centre via http://www.ccdc.cam.ac.uk/data_request/cif.
Supplementary Information accompanies this paper at http://www.nature.com/ naturecommunications

Competing financial interests: The authors declare no competing financial interests.

Reprints and permission information is available online at http://www.nature.com/ reprintsandpermissions/

How to cite this article: Asakawa, H. et al. Facile scission of isonitrile carbon-nitrogen triple bond using a diborane(4) reagent. Nat. Commun. 5:4245 doi: $10.1038 /$ ncomms5245 (2014).

(c) (1) (2) This work is licensed under a Creative Commons Attributioncc. other third party material in this article are included in the article's Creative Commons license, unless indicated otherwise in the credit line; if the material is not included under the Creative Commons license, users will need to obtain permission from the license holder to reproduce the material. To view a copy of this license, visit http:// creativecommons.org/licenses/by-nc-sa/4.0/ 